\title{
Perspectives of DBMT for monolingual authors on the basis of LIDIA-1, an implemented mock-up
}

\author{
Hervé BLANCHON \\ GETA, Institut IMAG (UJF \& CNRS) \\ BP 53, 38041 Grenoble Cedex 9, France \\ e-mail : Herve.Blanchon@ imag.fr
}

\begin{abstract}
DBMT' is researched here in the context of future systems for the general public, where a monolingual author wants to translate into several linguages. We have produced a complete mock-up, LIDIA-1, which demonstrates how a French IlyperCard ${ }^{\mathrm{M}}$ stack could be translated into German, Russian and English. We present the computationat, linguistic and ergonomic aspects of the mock-up, and discuss them in the perspective of building an operational prototype in the future.
\end{abstract}

\section{Keywords}

Interactive MT, DBM'T for monolingual author, Interactive disambiguation, Production of disambiguation dialogues, Distributed architecture, Whiteboard approach

\section{Introduction}

Our I,IDIA project aims at studying the concept of 'l'ersonal Machine 'Translation', or more precisely, DBMT' for monolingual authors [Boitet \& Blanchon 1993], in a multilingual setting.

We have now completed the first implementation of a mock-up, LIDIA-1. Working on a mock-up lirst, and not on a prototype, has made it possible to tackle all aspects of such future systems, computational, linguistic and ergonomic. liven if we conld not solve all problems, we fell they are put in perspective. Almost all other attempts in the direction of DBMT have considered only some aspects of the paradigm, leading to unbalaneed and sometimes inadequate atchitectures.

Before a demonstration which shows the principles of the translation process, we present an overview of the context of the mock-up. 'Then, we give some more details about the mock-up itself, the implementation technigues used and the principles of the interactive disambiguation process. Finally, we discuss some important points (interface, implementation techniques and tools, and disambiguation process) of the nock-up in the perspective of building an operational prototype in the future.

\section{Framework}

\subsection{The DBMT}

Interactive M'l was first proposed in the sixties by M. Kaly for the MIND system [Kay 1973], and several projects experimented with variations of this design, notably the ITS project [Mclby 1981] at Provo $(75-81)$, the $\Lambda$ lvey $N$ tran project [Wood 1989] at Manchester $(85-87)$, the DLT project [Saller 1989) at Utrecht $(82-88)$, the Y.M' project [Rimon, et al. 1991] from 1989 at several IBM research centers, and the JETS project ['T'sutsumi, et al. 19931 fom 1989 at IBM Tokyo labs.

In KBMT-89 [Goodman \& Nirenburg 1991] at CMUCCI, questions were also asked by the "augmentor" if ambiguitics could not be solved by the ontology.

Among those projects where an interactive disambiguation component was integrated, we were inspired by:

the interface proposed in KBM'l'-89,

- He prattem-based disambignation process used for several ambignilies in IMT,

- the distributed architecture of JiTS.

\subsection{The LIDIA-1 mock-up}

We have chosen at well-delined situation as regard to the profile of the lask and the profile of the user. We have integrated the use of an interactive disambiguation process at the very beginning of the design. This means that the whole set of constraints was well established betore we started the implementation. The translation process organization is described in [Boitet \& Blanchon 1993].

In the scenario we propose, a monolingual lisench engineer creates technical documentation, in the form of an IlyperCard stack, on a midelle-range Macintosh, and lelps the systen translate it into linglish, (icman and Russian. We have opted for a distributed architecture (author workstation on a Macintosh and MT server on a mini-IBM-4361).

We have produced a demonstration stack about the linguisties ambignity we have chosen to cope with in French.

\subsection{The demonstation stack}

Our demonstration stack, called 'IJI)rA les histoires' is made of story cards (fig. 2) and treatment cards (fig. 1).

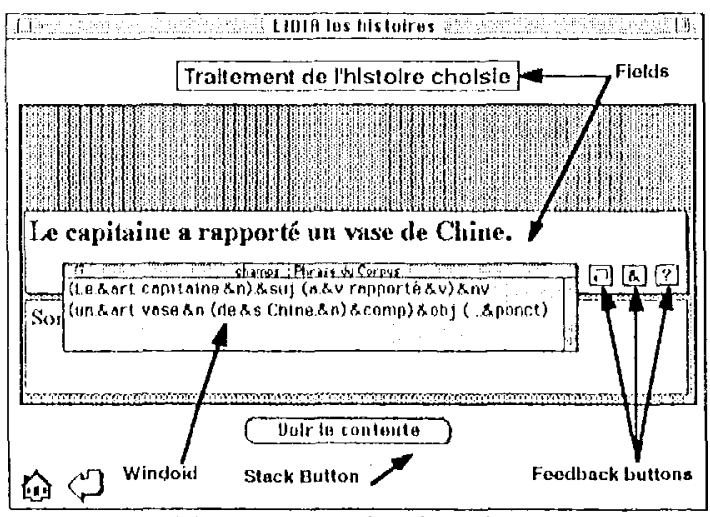

Figure I: a card and its objects 
A story card is a collection of two or three stories shating an ambiguous sentence. The author is supposed to solve the ambiguities through his understanding of the stories. Here is an example of a story card (sce translations ${ }^{1}$ ).

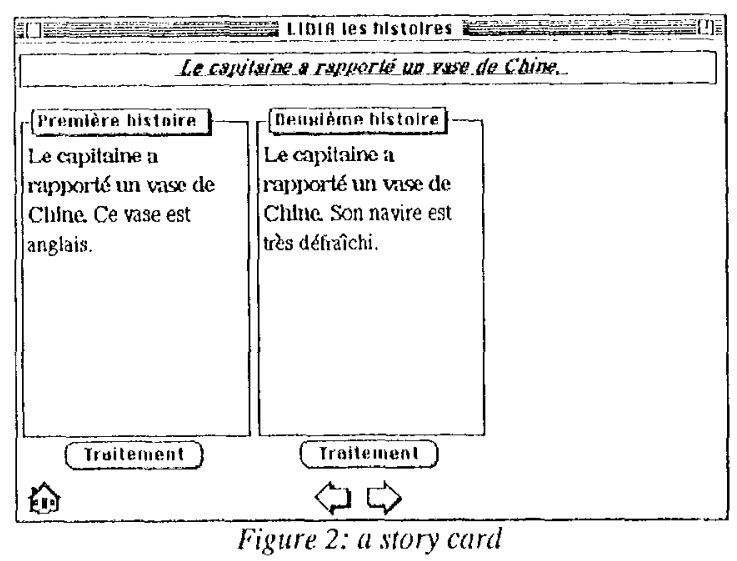

for the purpose of the demonstration, each story is presented in at treatment card, where the context of the ambiguous sentence may be shown or hidden. Here is the card for the story on the right.

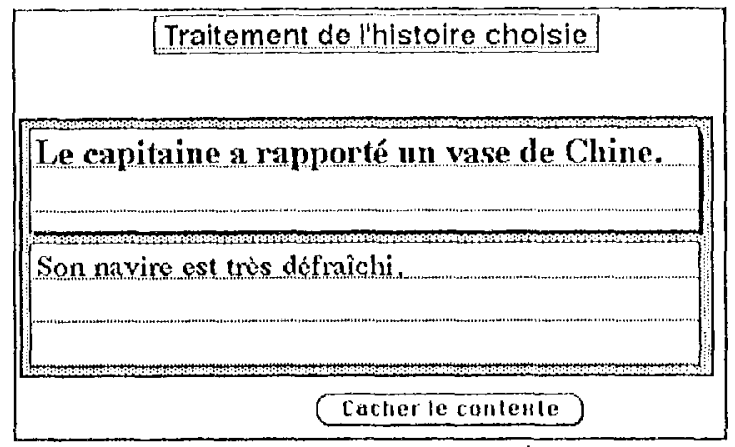

Figure 3: a treatment card

'l'o have the story translated, the user will ask for the translation of the fields of the treatment stack. Note that the user is never interrupted by a question. Objects show they are waiting for answers, and the user decides when and which question to answer.

\section{Demonstration}

The user can choose the selection tool $(\checkmark)$ and select the object to be translated (Fig. 4).

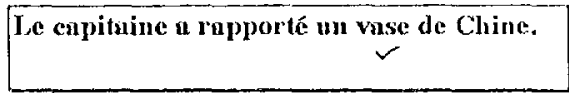

Figure 4: the selection of an object

The button of treatment state then appears. When clicking on it (fig 5), a windoid or pop-up window appears (lïg. 7).

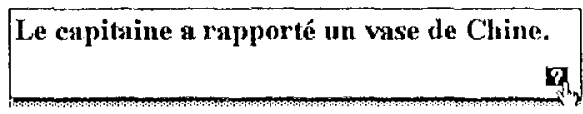

Figure 5: the user asks for the treatment state

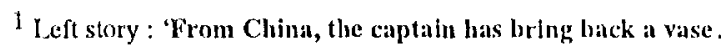
'This vase is English'. Right story: 'The captain has lring back a Chinese vase. I Iis boat is soiled."
'The ask in progress is displayed in bold, the previous ones in plain, and the following ones in italic. Thus, in ligure 7 the system is currently analyzing the text fragment.

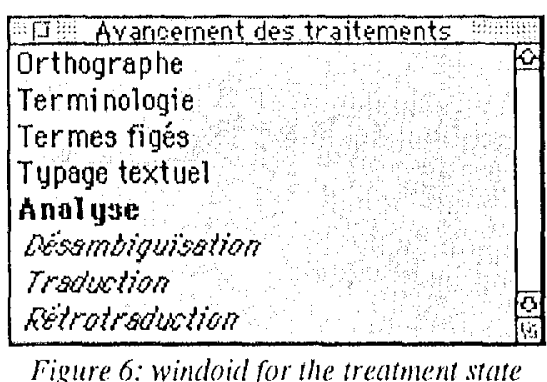

If the sentence has to be disambiguated, the author is asked to answer some questions. The author is advised a new question is ready by a new item in the menu Message and by a button which appears over the concerned object as in ligure 7. The user can choose to interact at once or later

\section{Le capitaine a rapporté un vase de Chine.

[एक]

Figure 7: the object have a question of terminology

$$
\text { [?!! }
$$

Suppose the user clicks on the [!] button. $A$ first question appears (Fig. 8).

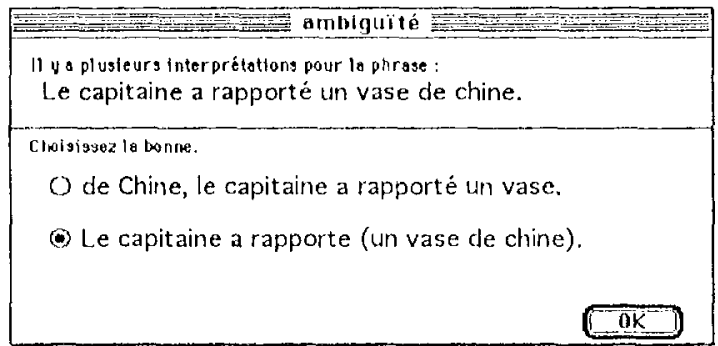

Figure 8: attachement disambiguation (story 2)

With the dialogue (Fig. 8), the author select the attachement of 'de Chine' (Chinese). Then, a second dialogue appears (lig. 9) where the author chooses the sense of 'capiaine'. The senses are found in larax, a multilingual lexical database mock-up [SĆrasset 1993].

H u o plusieurs sens acceptables pour le mot:
capitaine
Choisissez le bon.
O officier qui commande une compagnie d'infanterie, un
escadron de cavalerie, une batterie d'artillerie
Officier qui commande un navire de commerce
OChef d'une équipe sportive

Figure 9: word sense dismbiguation (story 2)

Once the disambiguation step has been performed, the user can ask for the annotated form of the text (lig. 10) which contains the syntactic class of each occurrence and the syntactic function of each pluase. 
(Le\&ert copitaine\&n)\&suj (o\&v rapporté.\&v)\&nv

(un \& ert vase \&n (de.\&s Chine.\&n)\&comp)\&obj (.\&ponct)

Figure 10: annotated form

These amnotations should help the user understand the structure produced by the analyser. We think that experienced users would like to shorteut some dialogues by inserting some disambiguation marks themselves.

To check the translation produced in each target language, the user can ask for the "reverse translation". From German and for the second interpretation of the example, he get:

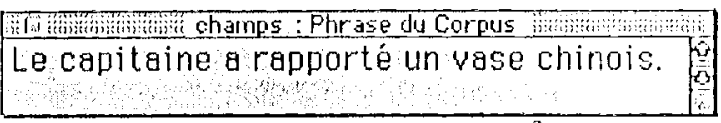

Figure 11: reverse translation ${ }^{2}$

Finally, the system produces a translated story catd.

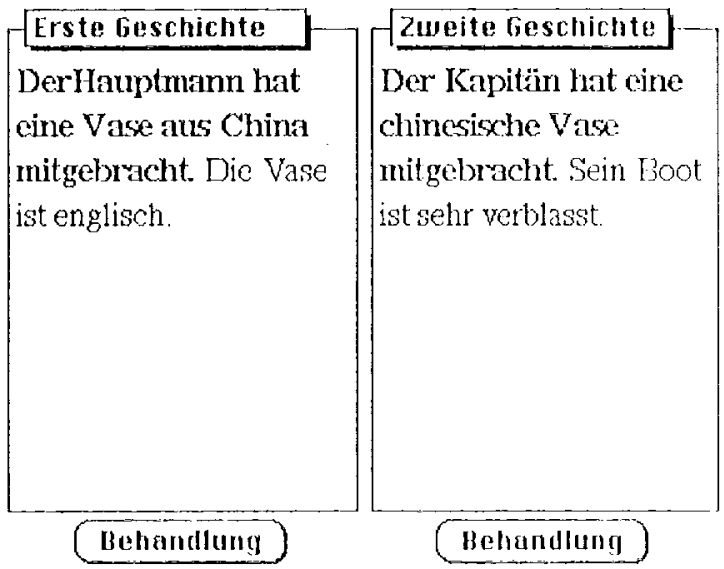

Figure 12: translation of the two stories inte German

\section{Other aspects}

$\Lambda s$ a demonstration can not show all external aspects of the mock-up, let us now give more detalis about the interface, the implementation techniques, and the methodology for disambiguation.

\subsection{Interaction tools}

\section{Lidia}

Traiter la sélection Traitement spécial...

Voir l'ástat du traitement Voir la rétrotraduction Voir les annotations

Palette Lidia

Préférences...

Construire piles cibles

figute 13: the ment object according to the set of preferences, process some object with a particular prelerence sed, slow the

2 "The eaptain has brought back a Chinese vase." treatinents' progress, show the reverse translation, show the amotations, show the palcte, modily the preferences and buikl the target stacks.

I

The user call also alsk for the trequent treatments with a palctte. In the lirst line are displayed the I,IDI $\Lambda$ lools (process the selected object, show the treatment progress, show the annotations and show the reverse translation). In the second line ate the browsing tools.

The translation process is divided into two steps: the standardisation and the clatification. Wo have seen the clarilication process during the demonstration, let us have a look on the standardization step.

\subsection{Implementation}

The implementation is characterized by the use of a distributed architecture, a whitcboard approach, and object-oriented technigues.

\section{a. Distributed architecture}

Tluree machines ( $\mathrm{rig} .15$ ) are involved in the translation process.

On the anthor's workstation the HyperCard Kemel sends and receives messiges from the LIDIA kernel which organises the translation process for each object. The LIDIA Kernel sends translation jobs to the Translation server via the Communication server. 'T'he LIDIA Kernel also asks to prepare the disambiguation guestions.

\section{b. Whiteboard approach}

for each object to be tamshated, the LIDIA Kernel creates a mirror object (a text file) in which are stored all information required by the translation process and necessary for the construction of the tatget stack. We distinguish between static and dynamic information. Static inlomation is what is attached by Iypercard to each object. It is necessary to constrted larget stacks. Jynanic information is any information nsed by I IDIA to tamslate the content of aln object.

These files can be considered ats whiteboards ans defined in [Seligman \& Boite 1994]. Unlike the blackboard, the whiteboard is accessed only by a coordinator (the LIDA Kernel), and not by the components (Disambiguation kernel and RemoteMacMain-Frame). The main advantage of this architecture is to allow ansy integration of existing new components without having to modily them.

\section{c. Object oriented techniques}

lexcept the lingware, all components use object-oricnted progrimming. The module for the Terminology, the idions and the Typage as the kernel of the Communication server are written in llyperlatk the Hypercard scripting langunge.

The LIDIA serveur is written with CT.OS (MCI.). Although encapsulated within the same environment, the LIDIA Kernel and the Disambiguation Kernel commnunicate by exchanging messages and can then be distributed. 


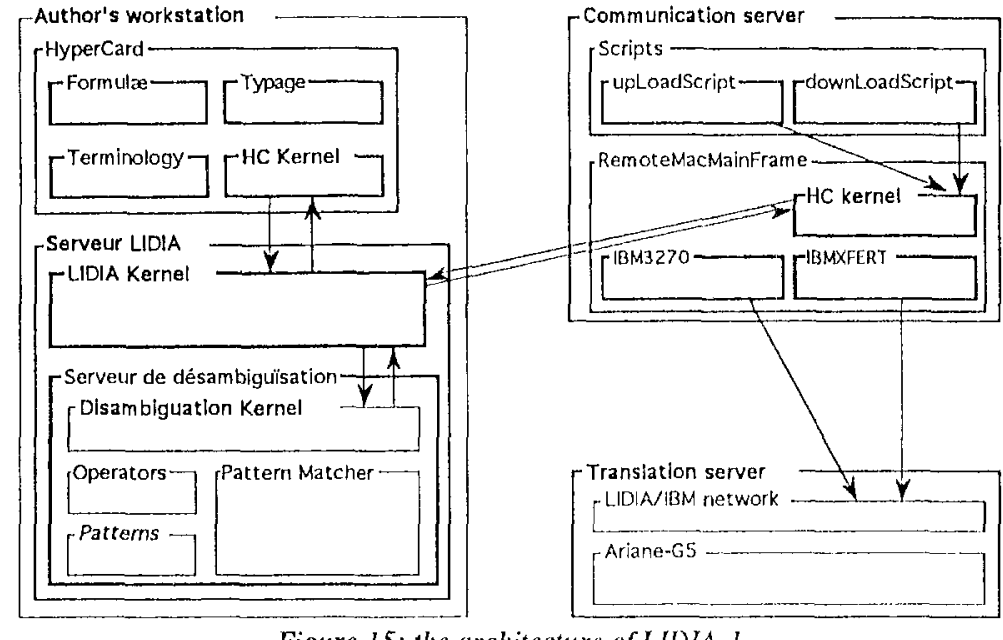

Figure 15: the architecture of LIDIA-I

The disambiguation process is orgamized around a pattern matcher [Blanction 1992]. For live out of the eight classes of ambiguity considered in the mock-up, we use a mechanism of pattern matching with unification of variables which allows to recognize the ambiguity and produce the disambiguation dialogue. $\Lambda$ dialogue construction method is associated with each pattern. These methods rely on a set of thirteen operators

ligure 16 shows the trees produced for the sentence 'Le capitaine a rapporté un vase de Chine.'

The palterns (Patron $12 \&$ Patron 13) used to recognize the ambiguity in our example are shown in Fig. 17.

The use of messages and object-oriented programming techniques is close to the actor model used in the context of distributed cooperative systems.

\section{3. disambiguation}

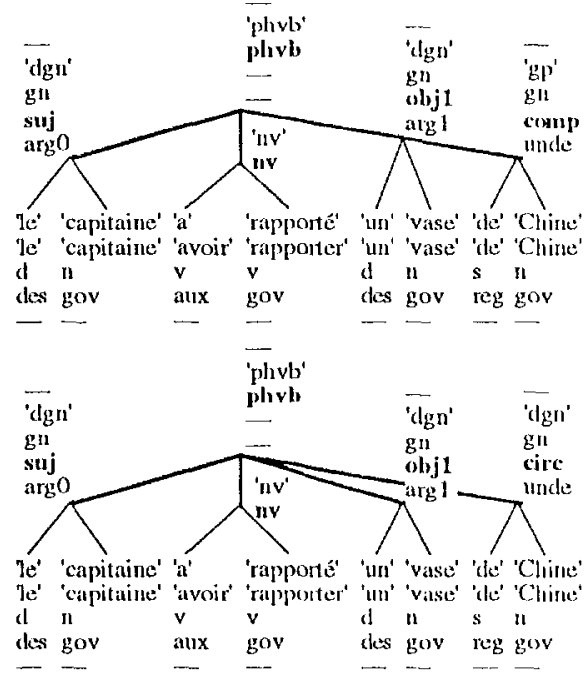

Figure 16: mullisolution, multilevel and concrete structure
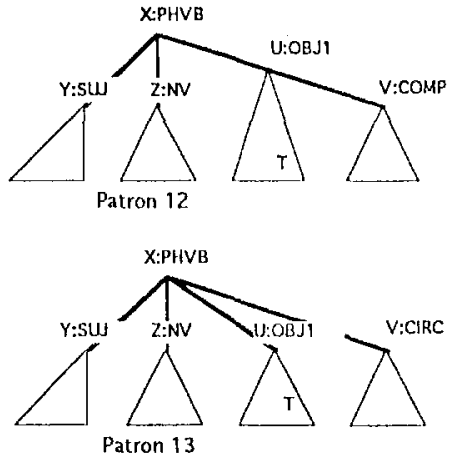

Figure 17: 2 patterns
12 is:

The method associated with pattern

'Ilexte(Y) Trexto(Y) Rarenthere('Texte('l'), Thxte(V))

which produces the following lext:

Le capitaine a rapporté (un vase de chine.)

The method associated widl pattern 13 is:

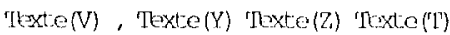

which produces the following text:

de Chine, le capitaine a rapporté un vase.

\section{Towards an operational prototype}

\subsection{Interface}

For a prototype, the modules for the terminology and the idioms should use, at least, a lemmatizer, and with the text categorization module they should not rely on llypercard any more (1.ig. 17).

Our implementation of the 'guided languages' idea is still very primitive. We hope to develop working techniçues from our studies on 'utterence styles' and 'text genres'.

The interfaces of the standardization modules ate only a first sketch. The iconic buttons used to ask for the user intervention have to be relesigned (we haven't found a good solution yet). On the other hand, the eursors for the IIIII tools and the feed-back buttons are homogenous and could be kept (lig. $1 \& 7$ ).

In a future work, it will be necessary to adlapt the dialogue type to the skills of the author. The kind of dialogne we have developed allows only the user to select the right analysis. $A$ new dialogue type conld allow the user to get information and examples about the ambiguity currently solved. The user could then change its text or insert disambiguating marks.

\subsection{Implementation techniques}

The current implementation in terms of software and hardware may be characterized as integrated, distributed and extensible. 
Using four servers (LIDIA, Di sambiguation, Communication, and Translation) collaborating through messages and texl files as made it relatively casy to integrate tools rumning in different hardware and/or software envirouments.

For using DBMT at home, a simple communication server could pilote a modem to request services from a IJIDIA server, exactly as a mail utility. With such an architecture, a low-cost personal computer would be usable for authoring and translating.

Using object-oriented programming techniques makes the system casy to customizc.

\subsection{Implementation tools}

The dictionaries used by the Ariane-G5 lingware are build from Parax [Serasset \& Blanc 1993]. For a prototype we need a more powertull and flexible tool, as also descriled in [Sćrasset \& Blanc 1993].

For developing the lingware, we have used Ariane-G5, designed for heuristic programming in the context of sublanguages. We plan to develop some new Specialized Languages for I.inguistic Programming, thereby working in the direction of 'ambiguous programming' |Boilet 1993].

\subsection{Disambiguation process}

It has been clear from the beginning that we would not be able to find, for each class of ambiguity we have chosen to solve, a unique resolution method. Keeping in mind the kind of dialogues we wanted, we have examined a large quantity of ambiguity configurations and have arrived al 9 problem patterns.

The use of a strategy, organizing the disambiguation process, the use of patterns and methods implemented with a set of basic operators make the process highly customizable. That's why we think about an environment for the description of disanbiguation process.

This environment integrates three modules: a module for the patterns definition, a module for the delinition of the dialogue production methods, and finally a module for the description of the disambigualtion strategy.

\section{Conclusion}

The implementation of our mock-up I.IDI $\Lambda-1$, first concrete experiment towards the DBMT' 'for everybody", has been done 'in breadth' at lirst, and 'in depth' on certain points. It was very important to tackle all the aspects. Previous experiments have shown the necessity of a broad conception for a M'T system to sueceed. During our work we have seen that the ergonomics goals can trigger computational and linguistic choices. The situation is the same for the computational or linguistic goals.

The idea of the interactive clarification approach in the context of natural language processing seems now to interest a real community. For M'l, the current work of [Wehrli 1993], [Yamaguchi, et al. 1993], and the ongoing work on JETS [T'sutsumi, et al. 1993] ate some good examples. For speech systems, the interactive clarification approach is also a solution as shown in [Frankish, et al. 1992] and proposed in [Ainsworth \& Pratt 1992] and [Saito 1992].
As far as the future is concened, we have begun to study multimoclal interactive disambiguation with ATR-ITL, in a more general framework than I.IWIA-1. We hope to get adequate support for developing a more larger-scale prototype in the next few years.

\section{References}

Ainsworth, W. A. \& Pratt, S. R. (1992). Feedlhack strategies for error correction in speech recognition system. in Intemational Journal of Man-Machine Studies. vol. 36(6): pp. 833-842.

IBlanchon, II. (1992). A Solution to the P'roblem of Interactive Disambigation. Proc. Coling-92. Nantes, France. 23-28 juillet 1992, vol. $4 / 4$ : pp. 1233-1238.

Boitet, C. (1993). Crucial Open Problems in Machine Translation and Interpretation. Proc. Symposium on Natural Language Processing in 'lhailand. Bangkok. 17-21 March 1993, vol. : . p. 1-29.

Boitet, C. \& Blanchon, Ir. (1993). Diatogue-based MT for monoling'ual authors and the III)IA project. Proc. NI.PRS'93. lukuoka, Jalon. 6-7 dkecmbre 1993, vol. 1/1 : pp. 208-222.

Prankish, C, Jones, D. \& Mapeshi, K. (1992). Dectine in accuracy of automatic speech recogrtition as a function of time on task: funigue or voice strift? in Intemational Iournal of ManMachine Studies, vol. 36(6) : pp, 797-816.

Goodmalı, K. \& Nirenburg, S. (eds), (1991). The KBMI Project: A case study in knowledge-based machine translation. Morgan Katufinann. Sim Mateo, California $331 \mathrm{p}$.

Kay, M. (1973). The MIND system. in Courant Computer Science Symposium 8 : Natural language Processing. Algorithmics Iress, Ine. New York. pp. 155-188.

Melby, A. K. (1981). Translators and Machines - Can they cooperate? in ME'TA. vol, $26(1):$ pp. 23-34.

Rimon, M. \& al. (1991). Advances in Machine Translation Research in INM. Proc. Machine Translation Summit III. Washington, D.C. 1-4 juillet 1991, vol. 1/1 : pl. 11-18.

Sadler, V. (1989). Working with analogical semantics: Disambiguation techniques in DIT. Fitoris P'ublications. Dordrecht, Ifollind. $256 \mathrm{p}$.

Saito, I1. (1992). Interactive Sipeech Understanding. Proc Coling-92. Nantes, lirance. $23-28$ juillet 1992, vol. $\mathbf{3 / 4}: \mathrm{pp}$ 1053-1057.

Sclipman, M. \& Isoitet, C. (1994). A "whiteboard" arrhitecture for antomatic speter transtation. Proc. International Symposium on Spoken Dialoggue. Waseda University, Tokyo. 1-12 noventhe 1994 , vol. : 1p. 4.

Súrasset, (3. \& Blanc, É. (1993). Une approche par acception

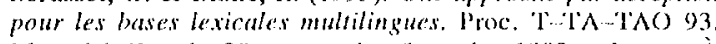
Montréal, Canaclit. 30 semplembre-2 octobre 1993, vol. : pp. $\hat{\Lambda}$ paraître.

Tsutsumi, T. \& al. (1993), Example-Based Approach to Machine Translation. Proce. Promières journes franco-japonatise sur la traductionassistée par ordinateor. Ambassade de lance au Japon, Tokyo, Jajon. 15-16 mats 1993, vol. 1/1 : pp. 161-169.

Welurli, li. (1993). Vers un systène de traduction interactif. in la traductique. Les presses de l'Université de Montréil,

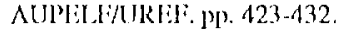

Wood, M. M. (1989). Iapanese for speakers of Enylish: The UMIST\%heffield Machinc Translation Project. in Recent Developments and Applications of Natural Langenage Processing. Kogan Page Limited. London. pip. 56-64.

Yamaguchi, M. \& al. (1993). An Interactive Method for Semantic Disambiguation in Sentences by Selecting lixamples. Proc. NII'RS'93. I'ukuoka, Japon. 6.7 décembre 1993, vol. : Pl). 208-222. 